\title{
Immunogenicity of monocomponent human and porcine insulin in newly diagnosed Type 1 (insulin-dependent) diabetic children
}

\author{
L. G. Heding1, M. O. Marshall', B. Persson', G. Dahlquist ${ }^{3}$, B. Thalme ${ }^{4}$, F. Lindgren ${ }^{3}$, H. K. Åkerblom ${ }^{5}$, A. Rilva , \\ M.Knip ${ }^{5}$, J.Ludvigsson ${ }^{6}$, L. Stenhammar ${ }^{7}$, L. Strömberg7, O. Søvik ${ }^{8}$, H. Bævre, ${ }^{8}$ K. Wefring 9 , J. Vidnes ${ }^{10}$, \\ J.J. Kjærgård ${ }^{11}$, P. Bro ${ }^{11}$ and P.H. Kaad ${ }^{11}$
}

\begin{abstract}
${ }^{1}$ Novo Research Institute, Copenhagen, Denmark, ${ }^{2}$ Department of Paediatrics, St. Göran's Hospital, ${ }^{3}$ Sachska Children's Hospital and ${ }^{4}$ Department of Paediatrics, Huddinge Hospital, Stockholm, Sweden,

${ }^{5}$ Children's Hospital, University of Helsinki, Helsinki, Finland, ${ }^{6}$ Department of Paediatrics, University Hospital, Linköping and ${ }^{7}$ Department of Paediatrics, Central Hospital, Norrköping, Sweden, ${ }^{8}$ Department of Paediatrics, Haukeland Hospital, Haukeland, ${ }^{9}$ Department of Paediatrics, Vestfold Hospital, Tønsberg, and ${ }^{10}$ Department of Paediatrics, Central Hospital, Oslo, Norway,

${ }^{11}$ Department of Paediatrics, Aalborg Hospital, Aalborg, Denmark
\end{abstract}

\begin{abstract}
Summary. The aim of the present study was to compare the immunogenicity of monocomponent human insulin with that of monocomponent porcine insulin in newly diagnosed Type 1 (insulin-dependent) diabetic children. One hundred and thirty-five patients at diagnosis of diabetes (age 1-18 years, mean age 9.3 years) were randomly allocated to treatment with either Monotard MC+ Actrapid MC or Monotard $\mathrm{HM}+$ Actrapid HM in a double-blind trial conducted in Sweden, Finland, Norway and Denmark. The human and porcine insulin groups were identical at diagnosis with respect to age, sex and measures of metabolic control. At all times the mean insulin antibody levels and the percentage of antibodypositive patients were lower in the human group compared
\end{abstract}

with the porcine group. At 3 and 12 months, the insulin antibody values were significantly lower in the human group than in the porcine group ( $p<0.05$, Wilcoxon's rank sum test). At 12 months, antibody values in the human group ranged from 0 to $1.2 \mathrm{U} / \mathrm{l}$ (mean $0.14 \mathrm{U} / \mathrm{l}$ ) and in the porcine insulin group from $0-5.2 \mathrm{U} / 1$ (mean $0.63 \mathrm{U} / 1)$. It is therefore concluded that human monocomponent insulin has a lower immunogenicity than porcine insulin of the same purity in newly diagnosed diabetic children during the first year of insulin treatment.

Key words: Type 1 diabetes in children, immunogenicity, monocomponent human insulin, monocomponent porcine insulin.
It is generally agreed that the purity of an insulin preparation influences the amount of insulin antibodies formed in diabetic patients. Thus, monocomponent (MC) porcine insulin induced less insulin antibodies than five times crystallized porcine insulin of the same formulation and the same was observed when mixed species ( $70 \%$ bovine, $30 \%$ porcine) preparations were administered in $\mathrm{MC}$ and five times crystallized quality [1]. From these results it was also evident that, irrespective of purity, bovine insulin was more immunogenic than porcine insulin given in the same formulation.

Human insulin is different from porcine insulin at position B30, but it was not foreseeable whether this difference would be of any significance in the immune response. When human insulin prepared by enzymatic transpeptidation from porcine insulin became available in large quantities, a Scandinavian multicentre trial was initiated. The major aims of this trial were to compare MC human and porcine insulins in the treatment of newly diagnosed Type 1 diabetic children, with respect to insulin-antibody formation, $\beta$-cell function and metabolic control. To exclude bias from patients, doctors and other personnel, the same randomized, controlled, double-blind design was used by all clinics participating. We present a preliminary report on insulin-antibody formation during the first year of treatment.

\section{Subjects and methods}

\section{Subjects and design of trial}

A total of 135 children with newly diagnosed Type 1 diabetes were included in the trial (Sweden 74, Finland 32, Norway 26 and Denmark 3).

The trial employed a double-blind, controlled design. At each clinic the patients were randomly allocated to treatment with one of two coded insulin preparations: human MC insulin (Novo) or porcine MC insulin (Novo). Actrapid and Monotard were used in each group. There was no significant difference between the two groups in age (human insulin group: mean age 9.2 years, range $1-15$ years; porcine insulin group: mean age 9.4 years, range $1-18$ years), sex (human insulin group: 39 males, 28 females; porcine insulin group: 41 males, 27 females) or in fasting blood glucose, urinary glucose, urinary ke- 


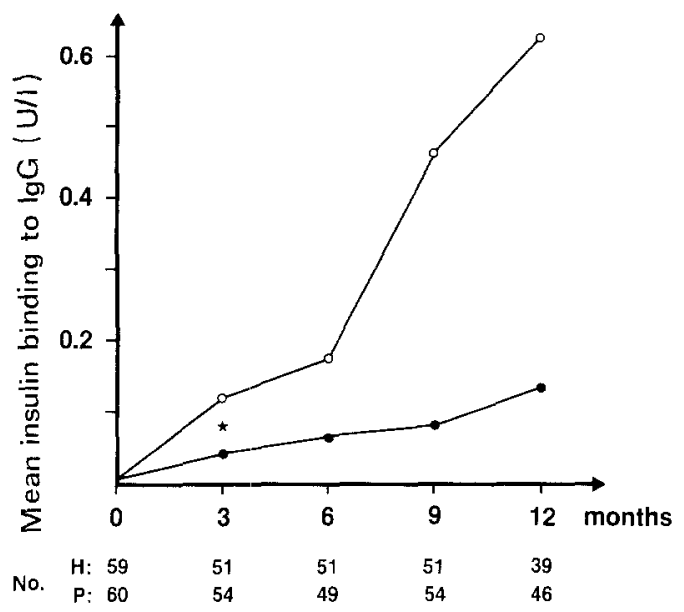

Fig. 1. Mean insulin antibody levels in human (-O) and porcine $(\mathrm{O}-\mathrm{O})$ insulin groups at different treatment times. $* p<0.05$

Table 1. Percentage of patients with insulin antibodies in human and porcine insulin groups

\begin{tabular}{llrrrrr}
\hline \multirow{2}{*}{$\begin{array}{l}\text { Insulin } \\
\text { treatment }\end{array}$} & & \multicolumn{7}{c}{ Months of treatment } \\
\cline { 3 - 7 } & & 0 & 3 & 6 & 9 & 12 \\
\hline Human & Number of patients & 59 & 51 & 51 & 51 & 39 \\
& Insulin antibody- & 2 & 24 & 29 & 39 & 44 \\
& positive (\%) & & & & & \\
Porcine & Number of patients & 60 & 54 & 49 & 54 & 46 \\
& $\begin{array}{l}\text { Insulin antibody- } \\
\text { positive (\%) }\end{array}$ & 2 & 39 & 43 & 44 & 59 \\
& & & & &
\end{tabular}

Insulin antibody-positive $=$ insulin binding to $\operatorname{IgG}>0.05 \mathrm{U} / 1$

tones or base excess at the time of diagnosis. Blood samples were taken at $0,3,6,9$, and 12 months and analysed blind at the Novo Research Institute for insulin antibodies. Data on metabolic control, insulin requirement and HLA-phenotypes will be reported separately.

\section{Methods}

Insulin antibodies were measured by the method of Christiansen [2] using ${ }^{125} \mathrm{I}$-bovine insulin as tracer. Statistical evaluation of differences between the two groups was carried out by the Wilcoxon rank sum test.

\section{Results}

Mean insulin antibodies in the human and porcine insulin groups during insulin treatment are shown in Figure 1. At diagnosis, before insulin treatment, all but one patient in each group (human insulin group: $0.11 \mathrm{U} / 1$; porcine insulin group $0.06 \mathrm{U} / \mathrm{l}$ ) had insulin antibody levels within the normal range $(<0.05 \mathrm{U} / 1)$. At 3,6,9 and 12 months mean insulin antibody levels were lower in the human insulin group than in the porcine insulin group. At 3 months insulin antibody levels ranged from 0 to $0.3 \mathrm{U} / 1$ in the human insulin group and from 0 to $0.9 \mathrm{U} / \mathrm{l}$ in the porcine insulin group. The corresponding ranges at 12 months were $0-1.2$ and $0-5.2 \mathrm{U} / 1$. The low- er distribution of values in the human insulin group at 3 and 12 months was statistically significant $(p<0.05$; Fig. 1).

When the percentage of insulin antibody-positive patients (levels $>0.05 \mathrm{U} / 1$ ) was compared between the two groups, it was found to be lower in the human than in the porcine insulin group at all treatment times, but the differences did not reach statistical significance (Table 1).

\section{Discussion}

The present results confirm two earlier reports of a lower immunogenicity of human insulin compared with porcine insulin $[3,4]$. However, the present study was performed double-blind with a simultaneously treated porcine insulin control group and using patients homogenous with respect to age and duration of diabetes. In contrast, in a previous study [3], the porcine control group was treated prior to the human group, while in the second study [4] the patients were heterogenous with respect to age and duration of diabetes. Nevertheless, these earlier results are in agreement with ours and it therefore seems safe to conclude that human insulin of the same formulation and purity has a lower immunogenicity than porcine insulin in newly diagnosed Type 1 diabetic patients. Our groups consisted exclusively of children, who are more actively antibody reactive than adults [5] and this further supports our conclusion.

The clinical importance of insulin antibodies formed after treatment with even highly purified insulin has been pointed out recently by Ludvigsson [6], who reported that among 50 diabetic children treated from the onset with porcine MC insulin 26 developed detectable amounts of insulin antibodies within 1 year. At 9 months the group without antibodies had higher Cpeptide responses to a meal, longer duration of remission and a lower insulin requirement than the group with antibodies. These results indicate that even the small amounts of insulin antibodies that we normally regard as harmless may have significantly negative effects, not only on acute glycaemic control and recovery from hypoglycaemia $[7,8]$, but also on $\beta$-cell function and, consequently, on metabolic control.

Acknowledgements. We wish to thank B. Hansen for her skilled technical assistance and A. Vølund for making the statistical calculations.

\section{References}

1. Schlichtkrull J, Pingel M, Heding LG, Brange J, Jørgensen KH (1975) Insulin preparations with prolonged effect. In: Hasselblatt $\mathrm{A}$, von Bruchhausen $\mathrm{E}$ (eds) Handbook of experimental pharmacology. Springer-Verlag, Berlin Heidelberg New York, pp 729-777

2. Christiansen AH (1973) Radioimmunoelectrophoresis in the determination of insulin binding to IgG. Methodological studies. Horm Metab Res 5: 147-154 
3. Schernthaner G, Borkenstein M, Fink M, Mayr WR, Menzel J, Schober E (1983) Immunogenicity of human insulin (Novo) or pork monocomponent insulin in HLA-DR typed insulin dependent diabetic individuals. Diabetes Care 6: (Suppl 1) 43-48

4. Fineberg SE, Galloway JA, Fineberg NS, Rathbun MJ, Hufferd S (1983) Immunogenicity of recombinant DNA human insulin. Diabetologia 25: $465-469$

5. Andersen $O O$ (1972) Insulin antibody formation $I$. The influence of age, sex, infections, insulin dosage and regulation of diabetes. Acta Endocrinologia (Copenh) 71: 126-140

6. Ludvigsson $\mathbf{J}$ (1984) Insulin antibodies in diabetic children treated with monocomponent porcine insulin from the onset: relationship to B-cell function and partial remission. Diabetologia 26: 138-141

7. Bolli G, Feo PD, Compagnucci P, Cartechini MG, Angeletti G, Santeusanio F, Brunetti P, Gerich JE (1983) Abnormal glucose counterregulation in insulin-dependent diabetes mellitus. Interaction of anti-insulin antibodies and impaired glucagon and epinephrine secretion. Diabetes 32: 134-141

8. Bolli GB, Dimitriadis GD, Brunetti P, Cryer PE, De Feo P, Gerich JE (1984) Circulating anti-insulin antibodies: effects on abnormal plasma insulin kinetics and glucoregulatory responses to hypoglycaemia in Type 1 (insulin-dependent) diabetes. Diabetologia 27 (Suppl): $74-76$

Dr. L.G. Heding

Novo Research Institute

Novo Alle

DK-2880 Bagsvaerd

Denmark 